\begin{tabular}{|l|l|}
\hline & \\
&
\end{tabular}

\title{
Disputa do fundo público em tempos de pandemia no Brasil
}

\author{
Public fund dispute in times of pandemic in Brazil
}

\author{
Evilasio Salvador ${ }^{1}$ \\ orcid.org/0000-0002-9474-374X \\ evilasioss@unb.br
}

Recebido em: 8/10/2020.

Aprovado em: $9 / 10 / 2020$.

Publicado em: 23/12/2020.
Resumo: Este artigo tem por objetivo analisar a execução orçamentária dos recursos do fundo público destinados especificamente para ações de combate à COVID--19, no âmbito do estado de calamidade pública que o Brasil vivencia, problematizando com a política de austeridade fiscal, em particular, os efeitos da Emenda Constitucional 95 nos gastos públicos. Para tanto, realizou-se um levantamento da execução orçamentária no sistema SIGA Brasil do Senado Federal e nos dados orçamentários disponibilizados no Painel Covid pelo Instituto Fiscal Independente (IFI). Os resultados da análise demonstram que as politicas de austeridade vêm ocasionando um efeito devastador nos gastos públicos brasileiro, implodindo a estrutura de recursos vinculados às políticas sociais definida na Constituição Federal de 1988. A execução das ações orçamentárias referentes ao novo coronavirus estão aquém do necessário, sobretudo, na política de saúde pública. O fundo público que o prioriza o pagamento de juros da dívida pública tem se mostrado insuficiente para fazer frente aos desafios e efeitos do agravamento das desigualdades sociais, do desemprego e fome que assola o pais em tempos de pandemia no Brasil.

Palavras-chave: Fundo público. Austeridade fiscal. Pandemia.

Abstract: This article aims to analyze the budgetary execution of public funds resources specifically destined for actions to combat Covid-19, within the scope of the state of public calamity that Brazil is experiencing, problematizing the policy of fiscal austerity, in particular, the effects EC 95 in public spending. To this end, it carried out a survey of budgetary execution in the SIGA Brasil system of the Federal Senate and budgetary data made available on the Covid Panel by the Independent Fiscal Institute. The results of the analysis demonstrate that austerity policies have been causing a devastating effect on Brazilian social spending. imploding the structure of resources linked to social policies defined in the 1988 Constitution. The execution of budgetary actions related to the new corona virus is below what is necessary, especially in public health policy. The public fund that prioritizes the payment of interest on public debt has proved insufficient to face the challenges and effects of the worsening social inequalities, unemployment and hunger that plagues the country in times of pandemic in Brazil. Keywords: Public fund. Fiscal Austerity. Pandemic.

\section{Introdução}

O mundo foi surpreendido, ${ }^{2}$ no ano de 2020 , pela pandemia do Corona Virus Disease (COVID-19), novo coronavírus, que já matou mais de um milhão de pessoas e, no Brasil, já provocou 150 mil mortes. A pandemia, acirrada pela crise do capital em contexto hegemônico do neoliberalismo e do capitalismo financeirizado, leva a uma profunda recessão econômica com aumento do desemprego e da desigualdade social global. 
Nessas circunstâncias, a disputa do fundo público ocupa lugar central, ainda mais na particularidade brasileira, marcada pelo comando de um governo de extrema direita, com uma política de austeridade fiscal e de contrarreformas do Estado.

No caso brasileiro, os efeitos da COVID-19 foram praticamente ignorados pelo governo e acabaram agravados pelas medidas de ajuste fiscal permanente e sua face mais recente de austeridade fiscal. Desde 2016, está um curso um Novo Regime Fiscal (NRF), determinado pela Emenda Constitucional (EC) 95, que limita por 20 anos os gastos correntes do governo, notadamente com as políticas sociais.

Ainda que o Congresso Nacional tenha aprovado, em maio de 2020, a EC 106, que institui Regime Extraordinário Fiscal, Financeiro e de Contratações para enfrentamento de calamidade pública nacional decorrente de pandemia relativa à COVID-19. Os recursos orçamentários têm sido aquém do necessário para fazer frente à calamidade sanitária, social e econômica que o país atravessa.

Este artigo tem por objetivo analisar a execução orçamentária dos recursos do fundo público, destinados especificamente para ações de combate à COVID-19, no âmbito do estado de calamidade pública que o Brasil vivencia, problematizando com a política de austeridade fiscal, em particular, os efeitos da EC 95 nos gastos públicos. Para tanto, realizou-se um levantamento da execução orçamentária no sistema SIGA Brasil do Senado Federal, que permite acesso aos dados do Sistema Integrado de Administração Financeira-SIAFI e a outras bases de dados sobre planos e orçamentos públicos. Além disso, utilizou-se dos dados orçamentários disponibilizados no Painel COVID pelo Instituto Fiscal Independente (IFI), órgão vinculado ao Senado Federal e responsável pela elaboração do Relatório de Acompanhamento Fiscal (RAF) dos gastos orçamentários extraordinários referentes ao combate à Covid-19.

Para tanto, este artigo, além desta introdução e das considerações finais, está organizado em mais duas seções. A primeira que problematiza a politica fiscal brasileira, destacando o ajuste fiscal permanente e apresentando os efeitos do NRF nos gastos sociais do orçamento público federal. Em seguida, analisa-se a execução orçamentária do combate a pandemia do COVID-19, no período de 7/4/2020 a 25/9/2020, com base nos créditos extraordinários no orçamento fiscal e da seguridade social.

\section{Fundo público e austeridade fiscal}

O fundo público envolve a capacidade que o Estado tem de mobilizar recursos, principalmente tributos $^{3}$, para realizar intervenções em políticas públicas, englobando as políticas econômicas e sociais, o que permite alterar ou conservar a realidade socioeconômica do país. O fundo público, em particular a sua face mais visivel, o orçamento público, é determinante para a acumulação do capital e a reprodução social no modo de produção capitalista, espelhando as contradições entre as classes sociais e a correlação de forças políticas na sociedade.

Para Salvador (2010), as múltiplas funções do Estado, presentes na reprodução do capital e viabilizadas por meio do fundo público, envolvem: as desonerações tributárias, os incentivos fiscais e a redução da base tributária para favorecer o investimento capitalista; a viabilização da reprodução da força de trabalho, por meio de salários indiretos e de políticas sociais; por recursos orçamentários para investimentos em infraestrutura, em investigação e pesquisa; e, no capitalismo contemporâneo, por uma transferência de recursos sob a forma de juros e amortização da divida pública para o capital financeiro, em especial para as classes dos rentistas.

Sendo, o fundo público, portanto, cada vez mais relevante para compreender a disputa dos recursos estatais em uma economia, sobretudo, em momentos de crise do capital. A disputa por recursos públicos, no âmbito do orçamento estatal, ocupa posição relevante no contexto de financeirização do capitalismo e do conjunto 
de contrarreformas do Estado, realizadas sob auspício das políticas neoliberais.

O neoliberalismo não se limita às medidas econômicas, pois é um "projeto político de classe, não somente um programa de políticas", conforme destaca Puello-Socarrás (2015, p. 24), sendo compreendido também na perspectiva de sistema normativo, que ampliou sua influência no mundo inteiro, estendendo a lógica do capital a todas as relações sociais e a todas esferas da vida, transformando profundamente as sociedade (DARDOT; LAVAL, 2016).

A política fiscal pode ser compreendida em dois segmentos: de um lado, a política de captação de recursos, em que se destaca a tributação; por outro lado, há a política de aplicação de recursos que se materializa no orçamento, a qual reflete os gastos e o dimensionamento das prioridades do governo; é uma das políticas econômicas mais importante para o neoliberalismo.

$\mathrm{Na}$ particularidade brasileira, pode-se afirmar que várias medidas institucionais, que vem ocorrendo desde 1993, marcam uma espécie de ajuste fiscal permanente. A política fiscal é a viga-mestre do Plano Real, elaborado em 1993. conjuntamente com a política monetária, baseada em elevadas taxas de juros e política de câmbio livre, sem controle de entrada e saida de divisas. A política fiscal, pelo lado das receitas governamentais, promoveu uma forte isenção dos impostos dos mais ricos e aumentou a regressividade do sistema tributário; e, pelo lado das despesas, viabilizou a realização de sucessivos superávits primários, como sinalizador de economia de recursos orçamentários para pagamento de juros da divida pública (SALVADOR, 2020a).

A questão do ajuste fiscal permanente tem ligações históricas com a teoria econômica neoclássica. Essa temática passa pelo debate sobre o tamanho, a distribuição da carga tributária, a apropriação dos recursos do fundo público, ou seja, do destino dos gastos orçamentários e dos investimentos do estado. As bases da atual matriz teórica econômica dominante no Brasil, que respalda a construção dos principais fundamentos das finanças públicas, têm sua origem no pensamento dos economistas clássicos (SANTOS, 2001) e são consolidadas na vertente neoclássica, que é a precursora século XIX da formulação neoliberal, no campo da teoria econômica, das finanças públicas.

A concepção neoclássica tem como pressuposto uma economia dominada por estruturas de mercado concorrenciais com mecanismos que corrigem automaticamente os desequilibrios de mercado. O Estado, desse modo, é compreendido erroneamente como um ente estranho ao sistema, ficando-lhe reservado um papel secundário de assegurar a ordem, a segurança interna e externa e a produção de alguns bens públicos não produzidos pelo mercado.

A partir da concepção de Keynes, introduzida no debate na década de 1930, o Estado passa a ocupar um papel relevante na economia, com destaque para a importância da produção pública no processo de acumulação capitalista e para os efeitos da política fiscal e monetária na garantia do pleno emprego.

Keynes foi um dos opositores da chamada Lei de Say, mas antes dele Malthus (1820) foi o formulador do princípio da demanda efetiva, devidamente recuperada por Keynes na década de 1930. Para Malthus, além da expansão da capacidade produtiva, era fundamental a demanda efetiva, pois o que leva os capitalistas a acumular é o desejo de produzir para auferir mais lucros.

De acordo com Santos (2001, p. 54),

\begin{abstract}
[...]. O que é crucial das implicações do principio da demanda efetiva nas finanças públicas é que Malthus desfaz o mito do caráter pernicioso da intervenção (defendido por Smith), do caráter improdutivo dos gastos e da ameaça do processo acumulativo do dispêndio público (ideia esboçada por Say) e a tributação como obstáculo à expansão das atividades produtivas (tal como acreditava Ricardo).
\end{abstract}

Para a concepção econômica neoclássica, o sistema tributário não pode romper o equilibrio de mercado, e os tributos devem obedecer aos princípios da "neutralidade" e da "equidade". No primeiro caso, os impostos não devem atingir as decisões dos agentes econômicos na alocação dos recursos nas economias, pois afetaria a eficiência. E o principio da equidade prevê que os impostos devem ser distribuidos de forma equilibrada entre os membros da sociedade, de forma a não alterar 
a estrutura de distribuição de renda, pois essa é considerada no modelo neoclássico como ótima antes de sua incidência, portanto, o sistema tributário não pode romper o "equilibrio" (OLIVEIRA, 2009).

Mas, na realidade

[...] as finanças públicas são algo muito mais amplo e complexo, sendo muito mais importante observar a composição dos gastos públicos (e da própria divida pública) e as tendências dinâmicas de sua realização ao longo do tempo pelo sistema econômico e social do que os meros saldos contábeis anuais que na verdade pouco ou nada nos dizem sobre a maturidade do arranjo institucional macroeconômico do pais em questão e tampouco sobre o significado do gasto ou do déficit público em si (CARDOSO JR; RAIMUNDO, 2020, p. 55).

No Brasil, a disputa dos recursos orçamentários e a hegemonia da sua direção, desde 1993, vem sendo marcada por uma política fiscal de ajuste permanente. No periodo mais recente, após o golpe de 2016, que tirou o mandato presidencial da presidenta Dilma e acendeu ao poder Michel Temer, acentua-se aquilo que na literatura econômica é denominado como política de austeridade, em particular, a fiscal.

No ajuste fiscal em curso desde 1993, instrumentos de desvinculações têm sido importantes para retirar recursos das fontes tributárias exclusivas da seguridade social, destacando-se no século 21, a Desvinculação de Recursos da União (DRU), que passou a vigorar a partir do ano 2000 , com sucessivas prorrogações. A mais recente ocorreu por meio da EC 93, que prorroga a DRU até 31 de dezembro de 2023 e amplia de 20\% para 30\% o percentual das receitas de tributos federais que podem ser usadas livremente.

Os mecanismos de desvinculação são alguns dos instrumentos que compõem o combo da política fiscal de ajuste permanente. Essa política tem como elementos centrais a redução dos impostos dos mais ricos na sociedade, a desoneração da carga tributária das empresas para viabilização da acumulação de capital e da retomada dos lucros, a busca da realização do superávit primário como indicador importante para os rentistas e a maior captura do fundo público para o pagamentos e juros e encargos da divida pública. Isso tudo aliado ao congelamento e à redução de gastos sociais e com servidores públicos no âmbito do orçamento.

Nessa direção, Teixeira e Boschetti (2019) destacam que a EC 95 de 2016 é um draconiano ajuste fiscal, que impede a expansão do orçamento, em particular, das despesas públicas discricionárias nas políticas de saúde, educação, ciência e tecnologia, infraestrutura, assim como colocou fim às aplicações de recursos mínimos em educação e saúde. Para as autoras, estão nesse bojo a contrarreforma previdenciária que suprimiu direitos e benefícios dos trabalhadora. Um conjunto de medidas tomadas em relação às políticas sociais

\begin{abstract}
[...] acabam com a concepção de seguridade social ampliada e reduzem vários direitos sociais ao tornar mais penoso o acesso ao seguro-desemprego, abono salarial, ao seguro-defeso, à pensão por morte, ao auxilio-doença, à aposentadoria por invalidez $e$ ao auxilio-reclusão. Fazem parte ainda desse "ajuste fiscal permanente" a contrarreforma trabalhista, a lei da terceirização, a criação do programa criança feliz, a regulamentação das Comunidades terapêuticas em detrimento de equipamentos públicos no âmbito da saúde mental (TEIXEIRA; BOSCHETTI, 2019, p. 72).
\end{abstract}

Rossi, Dweck e Oliveira (2018, p. 7) definem a "austeridade como uma política de ajuste da economia fundada na redução dos gastos públicos e do papel do Estado em suas funções de indutor do crescimento econômico e promotor do bem-estar social". Conforme os autores, essa prática política, retomada em 2015, ainda no governo Dilma Rousseff, como um plano de ajuste de curto prazo na economia brasileira, passa a definir o tamanho do setor público de forma estrutural a partir da EC 95. Com isso, o Brasil entra na era da austeridade. A austeridade fiscal é, portanto, a face contemporânea da política de ajuste fiscal permanente em curso no país.

Com a chegada do presidente Temer ao poder, ocorre um recrudescimento da ofensiva do capital, voltando com carga a ortodoxia neoliberal com brutal corte de direitos sociais, sobretudo, no campo do financiamento das políticas públicas, como denota o Novo Regime Fiscal (NRF), aprovado pela Emenda Constitucional 95. O NRF inviabiliza a vinculação dos recursos para as políticas sociais nos moldes desenhado na CF de 1988, ao congelar as 
chamadas despesas primárias do governo lexceto as despesas financeiras com o pagamento de juros da divida) por vinte anos, limitando-se a correção pela inflação. ${ }^{4}$ Conforme a regra proposta no NRF (EC 95), "os gastos públicos não vão acompanhar o crescimento da renda e nem da população, em um país cujo gasto per capta ainda é muito baixo" (DWECK; SILVEIRA; ROSSI, 2018, p. 48).

Os dados da execução orçamentária, a partir de 2016, revelam os efeitos acachapantes da EC 95 sobre as políticas sociais. Em levantamento realizado no Sistema SIGA Brasil, constata-se que o total do orçamento pago (fiscal mais seguridade social, excetuando a rolagem dos títulos da divida pública) apresentou um pequeno crescimento real de 2,6\% acima da inflação5 no periodo de 2016 a 2019. Todavia, diversas funções orçamentárias diretamente relacionadas ao Estado Social, que buscam garantir direitos no âmbito das politicas públicas, apresentaram um encolhimento em termos reais no período em tela (SALVADOR, 2020b).

Uma das quedas mais expressivas ocorreu na função Direitos da Cidadania, que, em 2016, teve um orçamento pago de R $\$ 2,17$ bilhões e decresce para menos de R\$ 1 bilhão em 2019, isto é, uma queda real de $57,44 \%$, em valores deflacionados pelo IPCA (SALVADOR, 2020b). Convém lembrar que estão vinculados nessa função orçamentária programas de garantia e defesa de direitos humanos no Brasil, de igualdade racial e de gênero, o que demonstra praticamente o abandono governamental dessas políticas públicas a partir de 2016.

A EC 95 sepulta a vinculação dos recursos obrigatórios, no âmbito da União, para educação e saúde a partir de 2018. Por exemplo, é o fim da vinculação de $18 \%$ dos impostos para educação. O orçamento federal da educação, em 2019, ficou, pela primeira vez desde 2016, abaixo de R\$ 100 bilhões pagos. No período de 2016 a 2019 , apresenta uma perda real de $12,57 \%$, saindo de R \$ 112,71 bilhões para R\$ 98,54 bilhões no ano passado, como consequência direta dos cortes nos recursos orçamentários das instituições federais de educação e o represamento dos concursos públicos na carreira de magistério de nível superior, conforme Salvador (2020b).

Na mesma pesquisa, destaca-se que a função orçamentária trabalho teve um encolhimento real de $8,85 \%$, sendo que no seu orçamento está o pagamento do benefício seguro-desemprego, isso é um paradoxo diante do crescimento exponencial do desemprego no país, agravado nos tempos de pandemia.

Os gastos com saúde, tão necessários na crise atual, agravada pelo coronavírus, mostra como o país estava despreparado para a pandemia. Os gastos e investimentos na função saúde, no âmbito do orçamento da seguridade social, estão praticamente congelados desde que entrou em vigor a EC 95

No periodo de 2016 a 2019, a função orçamentária saúde apresenta uma insignificante evolução de 0,39\%, saindo de R\$118,63 bilhões, em 2016, para R\$ 119,10 bilhões, em valores pagos em 2019, já deflacionados pelo IPCA, conforme Salvador (2020b). Para Vieira e Benevides (2016), o congelamento do gasto federal com saúde, na EC 95, implicará um agravamento das dificuldades para o financiamento do Sistema Únicos de Saúde (SUS), pois estados e municípios não conseguirão repor a perda de recursos que deixarão de ser aportados pela União

Conforme Fagnani (2018, p. 59), a austeridade fiscal marcada pela asfixia financeira da EC 95/2016 e pela DRU leva a destruição do marco civilizatório brasileiro, em que encontra na seguridade social o "mais importante mecanismo de proteção social do País e poderoso instrumento do desenvolvimento". Ainda cabe registrar o desmonte que se operou no financiamento da seguridade social, por meio da DRU e das Renúncias Tributárias, que foram usadas para atender aos interesses do capital, retirando os recursos que deveriam ser da saúde, previdência e assistência social (SALVADOR, 2017).

Por outro lado, chama atenção que no mesmo periodo desse encolhimento dos gastos sociais,

\footnotetext{
4 A EC 95 estabeleceu para o exercício de 2017 que a despesa primária paga no exercício de 2016, incluídos os restos a pagar pagos e demais operações que afetam o resultado primário será corrigida no limite de 7,2\% e para os exercicios posteriores, ao valor do limite referente ao exercicio imediatamente anterior, corrigido pela variação do Índice Nacional de Preços ao Consumidor Amplo (IPCA), publicado pelo Instituto Brasileiro de Geografia e Estatística (IBGE).

5 Em valores deflacionados pelo IPCA-IBGE.
} 
o Brasil vem destinando cada vez mais recursos para as forças armadas. Os dados da pesquisa mostram que no período de 2016 a 2019, a função orçamentária Defesa Nacional saltou de R\$67,8 bilhões, em 2016, para um orçamento pago, em 2020, de 78,5 bilhões, em valores já deflacionados pelo IPCA (SALVADOR, 2020b).

Um dos elementos essenciais no conflito distributivo do fundo público diz respeito a captura de recursos para o pagamento de juros e amortização da divida pública, o que está diretamente relacionado à financeirização da riqueza e as mudanças na proteção social no capitalismo contemporâneo. Com a financeirização da riqueza, os mercados financeiros passam a disputar cada vez mais recursos do fundo público, pressionando pelo aumento das despesas financeiras do orçamento estatal, o que passa pela remuneração dos títulos públicos emitidos pelas autoridades monetárias e negociados no mercado financeiro, os quais se constituem importante fonte de rendimentos para os investidores institucionais.

Para tanto, a EC 95 conseguiu viabilizar o congelamento das despesas primárias e priorizar o pagamento das despesas financeiras com juros, encargos e amortização da dívida pública com primazia no orçamento público. Enquanto isso, o orçamento fiscal e da seguridade social apresentou um crescimento real de somente 2,6\% acima do IPCA. No período de 2016 a 2019 . as despesas com juros e encargos da divida pública cresceram 8,5 vezes mais. Com isso, em 2016, o pagamento de juros e encargos da divida, que foi de $\mathrm{R} \$ 242,61$, aumentou para $\mathrm{R} \$ 287,57$ bilhões, em 2019, um crescimento real de 22,57\%. O pagamento efetivo das despesas com juros e amortização da divida pública consomem $1 / 4$ do orçamento público, conforme Salvador (2020b).

O efeito perverso da EC 95 será a destruição dos pilares do estado social no Brasil, no molde desenhado na Constituição Federal (CF) de 1988, que assegurou, ainda que de forma limitada, os recursos para financiamento das políticas sociais. A CF de 1988 estabeleceu gastos mínimos obrigatórios com saúde e educação pelos entes da federação e recursos vinculados as políticas da seguridade social (previdência, assistência social e saúde), seguro-desemprego e para os fundos de participação dos estados e dos municipios.

Com isso, conforme estudo do Instituto de Pesquisa Econômica Aplicada (Ipea), o Gasto Social Federal (GSF) apresenta uma trajetória de crescimento, saindo de 11,24\% do PIB, em 1995. para $15.54 \%$, em 2010, ou ainda, um crescimento real $172 \%$, acima da variação do IPCA (CASTRO et al., 2012). Em conformidade com a metodologia do Instituto, o GSF refere-se a um conjunto de ações dentro do Orçamento Geral da União (OGU) nas áreas: alimentação e nutrição, assistência social, beneficios dos servidores públicos federais, cultura, desenvolvimento agrário, educação, emprego e defesa do trabalhador, habitação e urbanismo, previdência social, saneamento e saúde.

Na mesma direção, Dweck, Silveira e Rossi (2018) apontam que o gasto primário do governo central cresceu de $14 \%$ para $19 \%$ do PIB, no período de 1997 a 2017, refletindo a regulamentação dos direitos sociais acordados na CF de 1988. A simulação das despesas do governo federal com a EC 95, feita pelos autores, aponta para redução no gasto primário de $19,54 \%$ do PIB (2017) para 12,42\% do PIB, em 2036.

$\mathrm{Na}$ realidade, conforme vimos na teoria econômica, a ideia de austeridade fiscal é uma tese antiga e sem fundamentos na realidade concreta, corroborando agravamento da crise do capital, o que ganha tons dramáticos no contexto da pandemia mundial, pois serão acentuadas as desigualdades sociais, o desemprego, a queda da renda dos trabalhadores, a fome e a miséria no Brasil e no paises que seguem a ladainha do ajuste fiscal.

O conceito de equilíbrio fiscal foi resgatado por Milton Friedman nos anos 1950 do século XX no âmbito do arcabouço teórico de cunho monetarista (CARDOSO JR; RAIMUNDO, 2020). O que parecia estar completamente desacreditado, sobretudo após a crise de 2008, mesmo por aqueles economistas que fazem parte dos círculos do pensamento dominante na economia é retomada com força no Brasil e agora de maneira persistente sob a batuta do ministro Paulo 
Guedes e seu ultraneoliberalismo.

Para Cislaghi (2020), o ultraneoliberalismo é o novo patamar em curso do neoliberalismo financerizado. A sua origem encontra-se na crise capital de 2008 e a sua conformação ocorre na década seguinte com um novo bloco histórico, que permitiu a chegada no poder de governos neofacistas, em vários lugares do mundo. Conforme a autora, a partir de 2010, essa nova face do neoliberalismo é "reacionária, racista, misógina, que retoma sua experiência inicial da ditadura chilena da década de 1980, inclusive ressuscitando personagens do período como Paulo Guedes, Ministro da Economia brasileiro desde 2019" (CISLAGHI, 2020).

Para Blyth (2017), a austeridade é uma ideia perigosa, provocando cortes orçamentários e, por onde tem sido adotada, vem deixando um rastro de enorme destruição, não se limitando, obviamente, a problema restrito a ordem econômica, mas a efeitos sociais traumáticos, com a erosão daquilo que o autor denomina como "coesão social". O dogma da austeridade, para Streeck (2018), restringe a autonomia dos governos nacionais no tocante às políticas econômicas e sociais, aumentando a descrença na democracia liberal.

O projeto ultraneoliberal em curso no Brasil de hoje, trará efeitos "dramáticos para os trabalhadores e certamente imprevisiveis e dependentes do desenrolar da luta de classes" (CISLAGHI, 2020).

Esse quadro aponta o acirramento das disputas entre as classes e frações de classes em torno do fundo público, principalmente no contexto da pandemia da COVID-19 e nas limitações impostas pela EC 95.

\section{Execução orçamentária das ações destinadas ao combate da pandemia (COVID-19)}

Em 8 de maio de 2020, o Congresso Nacional promulgou a Emenda Constitucional (EC) 106, que institui Regime Extraordinário Fiscal, Financeiro e de Contratações para enfrentamento de calamidade pública nacional decorrente de pandemia relativa à COVID-19. A EC 106 ficou conhecida como "orçamento de guerra" e permite a separação do orçamento e dos gastos realizados para o combate à pandemia de coronavírus (COVID-19) do orçamento geral da União (Fiscal, da Seguridade Social e de Investimentos).

Antes disso, o Congresso Nacional já tinha aprovado, em março de 2020, o estado de calamidade pública, o qual já permitia ao governo gastar acima dos limites estreitos, definidos pela meta de superávit primário para este ano (CARDOSO JR; RAIMUNDO, 2020).

O art. $3^{\circ}$ da EC 106, que trata da execução orçamentária e financeira, define que as proposições legislativas e os atos do Poder Executivo com propósito exclusivo de enfrentar a calamidade e suas consequências sociais e econômicas não podem implicar em aumento de despesa permanente (PALOS et al., 2020). Assim, durante a vigência da pandemia, essas iniciativas estão dispensadas da observância das limitações legais quanto à criação, à expansão ou ao aperfeiçoamento de ação governamental que acarrete aumento de despesa e concessão ou ampliação de incentivo ou benefício de natureza tributária da qual decorra renúncia de receita.

O financiamento das ações para enfrentamento da pandemia advinda da COVID-19 poderá ser realizado por meio da abertura de créditos orçamentários extraordinários, que é destinado ao atendimento de despesas imprevisiveis e urgentes, como as decorrentes de guerra, comoção interna ou calamidade pública, conforme Piscitelli; Timbó e Rosa (2006).

Com isso, durante o período de calamidade pública nacional, a EC 106 dispensou o Poder Executivo do cumprimento da chamada regra de ouro do orçamento público, prevista no artigo 167, inciso III, da Constituição Federal, que proíbe a realização de operações de créditos que ultrapassem o montante das despesas de capital, exceto as autorizadas mediante créditos suplementares ou especiais com finalidade especifica, aprovadas pelo Congresso Nacional. ${ }^{6}$

6 Essa vedação foi reafirmada pela Lei de Responsabilidade Fiscal (LRF), no $\S 3^{\circ}$, do artigo 32, que estabelece critérios de contabilização para os recursos de operações de crédito das despesas de capital. 
A vedação, reforçada pelo art. $32, \S 3^{\circ}$, da Lei de Responsabilidade Fiscal (LRF), reflete o entendimento de que o governo só pode emitir dívida para financiar investimentos ou rolar o pagamento de amortização de dividas passadas. De acordo com a EC em tela, durante o período de calamidade pública, o governo ficará dispensado da vedação prevista no inciso III do artigo 167 da CF.

Para Cardoso Jr. e Raimundo (2020, p. 62):

[...] a regra de ouro já se mostra, há muito tempo, uma norma fiscal completamente inadequada. Baseada em um conceito econômico ultrapassado, que valorizava unicamente os investimentos em capital físico, a regra de ouro prejudica a promoção dos direitos sociais e a criação e manutenção de capacitação humana. O enfrentamento à crise gerada pela pandemia exige, essencialmente, a elevação de despesas cor- rentes (tais como saúde e transferências), o que é absolutamente incompativel com a regra de ouro, que veda a ocorrência de déficit corrente. É importante lembrar que o próprio Tesouro Nacional, além de organismos internacionais e estudiosos do assunto, já propuseram a extinção dessa regra, tamanha a sua inadequação à realidade das finanças públicas.

O que está por detrás desta norma é o falacioso entendimento que a gestão estatal das finanças públicas deve ser igual à administração do orçamento doméstico ou empresarial. Trata-se de um mito, pois as familias e as empresas "ao contrário do governo, não emitem moeda e nem títulos públicos, bem como não controlam a taxa de juros sobre suas dívidas, como faz o Banco Central" (CARDOSO JR; RAIMUNDO, 2020, p. 59). Como destaca Behring (2020), "a escassez é um mito vendido caro" em tempos de disputa acirrada do orçamento público, agravada pela pandemia.

A regra de ouro acaba por inviabilizar uma das opções para que o Estado possa financiar suas políticas públicas, que são as operações de crédito, pois o que deveria importar, no tocante à divida pública, deveria ser a finalidade da contração, os prazos de pagamento, a taxa de juros e o planejamento governamental, portanto, as condições de financiamento.
Com isso, o governo editou 35 Medidas Provisórias (MP) até 24 de setembro de 2020, como ações que implicam gastos orçamentários para o combate à pandemia de coronavírus (COVID-19) que compõem assim o chamado "orçamento de guerra" previsto na EC 106. Essas MPs tratam de ações e iniciativas para o enfrentamento da emergência de saúde pública; da ampliação do número de famílias beneficiárias do Programa Bolsa Família (PBF); do benefício emergencial de manutenção do emprego e da renda; do auxílio emergencial de proteção social a pessoas em situação de vulnerabilidade; da compensação aos estados e municipios pela perda dos fundos de participação; do financiamento da folha de pagamento de pequenas empresas; da conta de desenvolvimento energético; da integralização de cotas no Fundo Garantidor de Operações (FGO) para o Programa Nacional de Apoio às Microempresas e Empresas de Pequeno Porte (Pronampe); da manutenção de contrato de gestão com organizações sociais; do programa emergencial de acesso ao crédito; do auxílio financeiro a estados e municípios; do auxílio emergencial às instituições de longa permanência para idosos; enfrentamento da emergência de saúde pública em favor do MEC e do Ministério da Cidadania para o ENEM, ENCCEJA, Revalida e aquisição de cisternas para escolas rurais nas regiões Norte, Nordeste e Centro-Oeste; aporte para agente financeiro BNDES para a concessão de empréstimos no âmbito do Programa Emergencial de Acesso a Crédito PEAC - Maquininhas e; da contratação de profissionais de saúde por tempo determinado, para atender à necessidade temporária de excepcional interesse público.

As ações orçamentárias decorrentes dessas medidas provisórias estão organizadas na Tabela 1. que apresenta a execução orçamentária do combate a pandemia do COVID-19, no período de 7/4/2020 a 25/9/2020,7 com base nos créditos extraordinários no orçamento fiscal e da seguridade social.

\footnotetext{
Considera-se como a primeira medida, a MP 921 de 7/2/2020, que "abre crédito extraordinário, em favor do Ministério da Defesa, no valor de R\$11.287.803,00" para os fins de Enfrentamento da Emergência de Saúde Pública de Importância Internacional Decorrente do Coronavírus e a última, na Tabela 2, a MP 1004, de 24/9/2020, que abre crédito extraordinário, em favor do Ministério da Saúde, no valor de $\mathrm{R} \$ 2.513 .700 .000,00$.
} 
TABELA 1 - Execução orçamentária das ações destinadas ao combate da pandemia (COVID 19)

Valores em R\$ (1)

\begin{tabular}{lll}
\hline Ação - Descrição & Dotação Atual & Pago
\end{tabular}

Aporte para Agente Financeiro BNDES para a Concessão de Empréstimos no âmbito do Programa Emergencial de Acesso a Crédito PEAC - Maquininhas, devido à pandemia do COVID-19

Ativos Civis da União

Auxilio Emergencial Residual para Enfrentamento da Emergência de Saúde Pública de Importância Internacional Decorrente do Coronavírus (COVID-19)

Auxilio Emergencial de Proteção Social a Pessoas em Situação de Vulnerabilidade, Devido à Pandemia da COVID-19

Auxilio Emergencial às Instituições de Longa Permanência para Idosos - ILPIs, Devido à Pandemia da COVID-19

Auxilio Financeiro aos Estados, ao Distrito Federal e aos Municipios para Compensação da Variação Nominal Negativa dos Recursos Repassados pelo Fundo de Participação

Auxilio Financeiro aos Estados, ao Distrito Federal e aos Municipios relacionado ao Apoio Emergencial do Setor Cultural devido à Pandemia da Covid-19

Auxilio Financeiro aos Estados, ao Distrito Federal e aos Municipios relacionado ao Programa Federativo de Enfrentamento à Covid-19

Beneficio Emergencial de Manutenção do Emprego e da Renda

Benefícios Obrigatórios aos Servidores Civis, Empregados, Militares e seus Dependentes

Concessão de Financiamentos para o Pagamento da Folha Salarial, devido à Pandemia do COVID-19

Enfrentamento da Emergência de Saúde Pública de Importância Internacional Decorrente do Coronavirus

Financiamento da Infraestrutura Turística Nacional 


\section{Valores em R\$ (1)}

\begin{tabular}{|c|c|c|c|}
\hline Ação - Descrição & Dotação Atual & Pago & Execução (2) \\
\hline $\begin{array}{l}\text { Incremento Temporário ao Custeio dos } \\
\text { Serviços de Assistência Hospitalar e Am- } \\
\text { bulatorial para Cumprimento de Metas }\end{array}$ & $23.049 .729,00$ & $19.174 .076,00$ & $83,19 \%$ \\
\hline $\begin{array}{l}\text { Incremento Temporário ao Custeio dos } \\
\text { Serviços de Atenção Básica em Saúde } \\
\text { para Cumprimento de Metas }\end{array}$ & $43.059 .135,00$ & $34.152 .216,00$ & $79,31 \%$ \\
\hline $\begin{array}{l}\text { Integralização de cotas do Fundo Garanti- } \\
\text { dor para Investimentos - FGI para Peque- } \\
\text { nas e Médias Empresas no âmbito do } \\
\text { Programa Emergencial de Acesso a Crédito }\end{array}$ & $20.000 .000 .000,00$ & $15.000 .000 .000,00$ & $75,00 \%$ \\
\hline $\begin{array}{l}\text { Integralização de cotas no Fundo Garanti- } \\
\text { dor de Operações (FGO) para o Programa } \\
\text { Nacional de Apoio às Microempresas e } \\
\text { Empresas de Pequeno Porte (Pronampe) }\end{array}$ & $27.900 .000 .000,00$ & $27.900 .000 .000,00$ & $100,00 \%$ \\
\hline $\begin{array}{l}\text { Manutenção de Contrato de Gestão com } \\
\text { Organizações Sociais (Lei n 9.637, de } 15 \\
\text { de maio de 1998) }\end{array}$ & $20.000 .000,00$ & - & $0,00 \%$ \\
\hline $\begin{array}{l}\text { Transferência de Recursos para a Conta } \\
\text { de Desenvolvimento Energético (Lei nº } \\
\text { 10.438, de } 26 \text { de abril de 2002) }\end{array}$ & $900.000 .000,00$ & $900.000 .000,00$ & $100,00 \%$ \\
\hline $\begin{array}{l}\text { Transferência de Renda Diretamente } \\
\text { às Familias em Condição de Pobreza e } \\
\text { Extrema Pobreza (Lei n } 10.836 \text {, de 2004) }\end{array}$ & $3.037 .598 .000,00$ & $369.285 .445,00$ & $12,16 \%$ \\
\hline Total & $601.139 .591 .080,00$ & $412.779 .805 .320,00$ & $68,67 \%$ \\
\hline
\end{tabular}

Fonte: Instituição Fiscal Independente (IFI) e SIGA Brasil - Senado Federal. Elaboração Própria

Notas:

1 - Dados da execução orçamentária realizada até 25 de setembro de 2020.

2 - Refere-se a razão entre os valores pagos e autorizados.

A maior parte do financiamento das ações, detalhadas na Tabela 1, tem como fonte a emissão de títulos de responsabilidade do Tesouro Nacional (operações de créditos internas), que representa $54,32 \%$ dos créditos extraordinários emitidos, $19,6 \%$ de recursos ordinários, isto é, de impostos e o restante de outros fontes do Tesouro Nacional. ${ }^{8}$

Dos R\$ 601,13 bilhões já autorizados para ações destinadas ao combate da pandemia (COVID-19), foram pagos $\mathrm{R} \$ 412,78$ bilhões, conforme dados organizados na Tabela 2. Chama atenção a baixíssima execução orçamentária de algumas ações que seriam fundamentais para a garantia de uma proteção social mínima aos trabalhadores/as no contexto da pandemia. Como, por exemplo, a ação "Ativos Civis da União" como valor autorizado de R\$ 320,11 milhões e que foram pagos somente R\$ 10.905,23, isto é, uma pífia execução orçamentária de $3,41 \%$ (vide Tabela 1). Uma parte desse recurso está prevista no âmbito da MP 970, de 25/05/2020, que possibilitava ao Ministério da Saúde, por meio do Fundo Nacional de Saúde, a contratação de profissionais da saúde em locais fortemente afetados pela pandemia (RODRIGUES, 2020), evitando, assim,

8 Conforme dados do Painel do IFI. Disponivel em: https://datastudio.google.com/reporting/12071674-bd8c-4949-af82-504ce236bd5d/page/A11PB. Acesso em: 24 set. 2020. 
a interrupção de serviços de atendimento da população por carência de profissionais no Sistema Único de Saúde (SUS). A própria exposição de motivos da MP estimava a contratação de cerca de cinco mil profissionais de saúde por tempo determinado.

A MP 929 permitia o governo ampliar os recursos para o Programa Bolsa Familia (PBF) com autorização de gastos de até R \$ 3,04 bilhões com objetivo de "garantir a segurança alimentar das familias em condições de pobreza e extrema pobreza de forma mais rápida e eficaz", conforme a exposição de motivos que acompanhou a edição da medida em 25 de março de 2020. Contudo, o nível de execução dos recursos foi de apenas R\$ 369,29 milhões, ou seja, 12,16\% do autorizado (vide Tabela 1) e a MP 929 expirou o prazo em 22/07/2020, sem aprovação pelo Congresso Nacional.

As ações sob responsabilidade do Ministério da Saúde, o qual permaneceu por quatro meses com um ministro interino, têm sido marcadas pela morosidade na execução orçamentária, conforme pode ser observado na Tabela 2. Dos R\$ 47,04 bilhões já autorizados para "enfrentamento da emergência de saúde pública de importância internacional decorrente do Coronavírus", 25,28\% do orçamento não foi executado.

As análises que vêm sendo realizadas pela Comissão de Orçamento e Financiamento do Conselho Nacional de Saúde (Cofin/CNS) vem revelando letargia do Ministério da Saúde nas ações emergenciais de combate ao Coronavírus, que são fundamentais para a proteção à saúde no Brasil. O boletim Cofin/CNS (23/09/2020, p. 2) revela, com base nos dados do Sistema SIGA Brasil, que R\$ 17,4 bilhões estão ainda "sem uso" no Ministério da Saúde, que sequer realizou o empenho ${ }^{9}$ dos recursos orçamentários, sendo que parte desses recursos está disponivel desde abril de 2020 e deveria ser utilizada para a compra de respiradores, máscaras e outros itens necessários para a população, para os trabalhadores da saúde e para equipar as unidades de saúde pelo país.

O Auxilio Emergencial de Proteção Social à Pes- soas em Situação de Vulnerabilidade, devido à pandemia da COVID-19, representou, até 25/og/2020, $51,61 \%$ do montante pago nas ações orçamentárias destacadas na Tabela 2. Sendo que o Auxilio Emergencial Residual para Enfrentamento da Emergência de Saúde Pública de Importância Internacional Decorrente do Coronavirus teve 6,34\% dos R\$ 67,6 bilhões autorizados em 2/9/2020, pela MP 999, pagos.

Convém destacar que o governo encaminhou para o Congresso Nacional a proposta de auxilio emergencial no valor de apenas R\$200,00 por três meses a ser pago em razão do estado de calamidade pública e da emergência de saúde pública de importância internacional decorrente do coronavirus (COVID-19). Somente após pressão dos movimentos sociais ${ }^{10}$ no âmbito da sociedade civil organizada e a atuação dos partidos de oposição ao governo Bolsonaro, o valor do auxílio foi elevado para $\mathrm{R} \$ 600,00$, com a aprovação da Lei $n^{\circ} 13.982$, de 2 de abril de 2020, e regulamentada pelo Decreto $n^{\circ} 10.316$, de 7 de abril de 2020.

Para o recebimento dos valores do auxílio emergencial de R\$ 600 mensais, por três meses, ou de R\$1.200,00 mensais para mães de família monoparental, foram estabelecidos um conjunto de requisitos, conforme art. $2^{\circ}$ da Lei $n^{\circ} 13.982$, de 2 de abril de 2020:

Ter mais de 18 (dezoito) anos de idade;

a) não tenha emprego formal ativo:

b) não ser titular de benefício previdenciário ou assistencial ou beneficiário do seguro-desemprego ou de programa de transferência de renda federal, ressalvado o Bolsa Familia;

c) Ter renda familiar mensal per capita de até $1 / 2$ (meio) salário-mínimo ou a renda familiar mensal total seja de até 3 (três) salários-mínimos;

d) No ano de 2018, não pode ter recebido rendimentos tributáveis acima de $\mathrm{R} \$$ 28.559,70;

e) Que exerça atividade na condição de: microempreendedor individual (MEI);

9 O empenho é o primeiro estágio da despesa pública.

10 Destacam-se a atuação das entidades vinculadas as coalizações: Plataforma pela Reforma do Sistema Político; Renda Básica que Queremos; e Direitos Valem Mais. 
contribuinte individual do Regime Geral de Previdência Social; ou trabalhador informal, seja empregado, autônomo ou desempregado, de qualquer natureza, inclusive o intermitente inativo, inscrito no Cadastro Único para Programas Sociais do Governo Federal (CadÚnico) até 20 de março de 2020.

Os dados da Caixa Econômica Federal, em 1/9/2020, revelam que o auxilio emergencial foi pago para 67,2 milhões de beneficiários, ${ }^{11}$ o que equivale a 1/3 da população brasileira, revelando aumento da miséria e da pobreza no Brasil, sendo que cerca de 4,4 milhões de domicilios brasileiros sobreviveram, em julho/2020, somente com a renda do Auxilio Emergencial (IPEA, 2020). As projeções do Banco Mundial indicam que o Brasil voltou para "mapa da fome" e até o fim de 2020, 14,7 milhões estarão na extrema pobreza. ${ }^{12}$

Para Behring e Boschetti (2020):

O que se vislumbra é um processo acelerado e ampliado de assistencialização da pobreza, o que difere imensamente do direito à assistência social. Este último pode e deve compor uma politica de seguridade social, fundada em trabalho estável com direitos, previdência e saúde públicas e universais. Como direito social, programas de "renda básica universal" podem complementar ou substituir temporariamente a perda de direitos do trabalho, mas jamais terão a capacidade de reduzir desigualdades no acesso à riqueza socialmente produzida. Sua expansão expõe, na verdade, a incapacidade do capitalismo de superar suas crises.

Para as autoras, os programas de transferências de renda estão inseridos no âmbito de estratégias de assegurar a sobrevida dos trabalhadores, o fluxo do consumo e a disponibilização de uma força de trabalho de baixo custo para a exploração capitalista. Ao mesmo tempo, para quem recebe acaba sendo uma "uma questão de vida ou de morte, ainda mais em países como o Brasil, marcado pela informalidade, baixos e instáveis salários e precarização agressiva" (BEHRING; BOSCHETTI, 2020).

Essa letargia do governo em executar ações emergências no campo das políticas sociais e a demora em realização os pagamentos dos auxilios emergenciais, associado as inúmeras exigências, não ocorreu da mesma no atendimento dos interesses capital financeiro. O Banco Central, já início dos primeiros casos do COVID- 19 no Brasil, anunciou em 24 de março, medidas que liberaram 1,2 trilhão para o sistema financeiro e certamente foram decisivas para o lucro de 24,3 bilhões, no $1^{\circ}$ semestre de 2020, dos quatro maiores bancos em atuação no país. ${ }^{13}$ Aliás, a garantia dos recursos do fundo público ao Capital Portador de Juros e Capital Fictício segue como uma prioridade do governo brasileiro, conforme revelam os dados levantados junto ao Sistema SIGA Brasil. Até o dia 29 de setembro, do montante de R\$ 2,1 trilhões pagos da Lei Orçamentária Anual (LOA), R\$ 578,67 bilhões foram destinados ao pagamento de juros e encargos da divida (R\$ 311,36 bilhões) e amortização da dívida (R\$ 267,41 bilhões), representando $26,85 \%$ do total do orçamento de 2020, conforme a Tabela 2.

TABELA 2 - Valores pagos em R\$ na LOA 2020 (1)

\begin{tabular}{|c|c|}
\hline $\begin{array}{l}\text { Grupo de Natureza de } \\
\text { Despesa }\end{array}$ & Valores Pagos \\
\hline Amortização da dívida & $267.407 .574 .584,05$ \\
\hline Inversões financeiras & $89.813 .124 .391,03$ \\
\hline Investimentos & 10.253 .166 .251 .57 \\
\hline Juros e encargos da divida & 311.360 .406 .774 .71 \\
\hline Outras despesas correntes & $1.250 .960 .237 .463,81$ \\
\hline Pessoal e encargos sociais & 225.472 .501 .774 .56 \\
\hline Total & $2.155 .267 .011 .239,73$ \\
\hline $\begin{array}{l}\text { Amortização da Dívida } \\
\text { mais Juros e Encargos da } \\
\text { Dívida }\end{array}$ & $578.767 .981 .358,76$ \\
\hline Percentual (\%) sobre o total & $26,85 \%$ \\
\hline $\begin{array}{l}\text { Fonte: Sistema Siga Brasil; ela } \\
\text { Nota: } \\
1 \text { - Exclui a rolagem da divida. } \\
\text { ídos em } 29 / 09 / 2020 \text {. }\end{array}$ & $\begin{array}{l}\text { boração Própria. } \\
\text { Os dados foram extra- }\end{array}$ \\
\hline
\end{tabular}

\footnotetext{
11 Disponivel em: https://caixanoticias.caixa.gov.br/noticia/22998/caixa-ja-disponibilizou-as-cinco-parcelas-do-auxilio-emergencial-para-192-milhoes-do-bolsa-familia. Acesso em: 25 set. 2020

Disponivel em: https://ultimosegundo.ig.com.br/brasil/2020-04-20/COVID-19-lancara-mais-54-milhoes-de-brasileiros-na-extrema-pobreza-diz-estudo.html. Acesso em: 25 set. 2020.

Disponivel em: https://economia.uol.com.br/noticias/redacao/2020/08/07/bancos-gastam-mais-com-medo-de-calote-e-perdem-lucro.htm. Acesso em: 20 set. de 2020.
} 
Portanto, o valor destinado pelo fundo público aos rentistas é 40,22\% superior ao montante do orçamento destinado ao combate da pandemia do Covid-19\% (R\$165,89 bilhões), revelando claramente as prioridades no orçamento público brasileiro, mesmo em tempos de "orçamento de guerra".

As medidas no campo da austeridade fiscal devem novamente ocupar a agenda pública com o desenrolar da pandemia. Em particular, com o pacote de três Propostas de Emendas à Constituição (PEC) que compõem o Plano Mais Brasil, elaborado pela equipe econômica do governo e enviadas ao Congresso Nacional, em novembro de 2019.14 As propostas têm objetivo de reduzir gastos obrigatórios, revisar fundos públicos e alterar as regras do Pacto Federativo.

A PEC 188, por exemplo, busca inserir um parágrafo único no artigo $6^{\circ} \mathrm{da} C F$, que trata dos direitos sociais com a seguinte redação "será observado, na promoção dos direitos sociais, o direito ao equilibrio fiscal intergeracional". Com isso, "o referido parágrafo único, se aprovado, representará uma forma de relativização ou severa restrição dos direitos sociais fundamentais ao condicioná-los ao 'equilibrio fiscal intergeracional', mesmo sendo este um (pseudo) conceito, teórica e empiricamente, questionável" (CARDOSO JR.; RAIMUNDO, 2020, p. 50).

Uma das PECs que integra o Plano Mais Brasil estabelece que os fundos públicos da União, dos estados, do Distrito Federal e dos municípios serão extintos se não forem ratificados pelos respectivos poderes legislativos por meio de lei complementar específica até o final do segundo exercicio financeiro subsequente à data da promulgação da emenda constitucional.

Caso a PEC seja aprovada, deverão ser extintos cerca de 248 fundos, sendo a maioria (165) instituída antes da Constituição de 1988. Segundo o governo, a proposta permitirá a desvinculação imediata de cerca de R\$ 219 bilhões, que poderão ser utilizados na amortização da divida pública da União.

\section{Considerações finais}

O ajuste fiscal permanente e as recentes políticas de austeridade, notadamente, a EC 95/2016, vem ocasionando um efeito devastador nos gastos sociais brasileiro, implodindo a estrutura de recursos vinculados às políticas sociais definida na CF de 1988. A não priorização das políticas sociais no âmbito do orçamento público torna-se ainda mais grave no contexto da pandemia do novo coronavírus.

O combo do ajuste fiscal permanente, que cobra impostos sobre os mais pobres na sociedade em detrimento da tributação dos mais ricos, os quais surrupiam recursos da seguridade social via desvinculação e desoneração de recursos, está ainda mais fortalecido com a política de austeridade fiscal da EC 95, a qual assegura cada vez uma transferência sem precedentes de recursos públicos para a esfera da financeirização da economia. A situação deve se agravar ainda mais com o pacote de medidas econômicas enviadas em novembro de 2019 ao Congresso Nacional.

Ainda que o Congresso Nacional tenha aprovado um "orçamento de guerra", ele tem se mostrado insuficiente para fazer frente aos desafios e efeitos do agravamento das desigualdades sociais, do desemprego e da fome, os quais assolam o país. As ações orçamentárias executadas estão aquém do necessário, sobretudo, na política de saúde pública. Por outro lado, segue em curso a drenagem de recursos do fundo público para o pagamento de juros e amortização da dívida pública, que supera, com folga, em 2020, o montante das ações orçamentárias, asseguradas por medidas provisórias que abrem créditos extraordinários no orçamento fiscal e da seguridade social, para ações emergenciais para enfretamento da calamidade pública da COVID-19.

\section{Referências}

BEHRING, Elaine. Escassez é um mito vendido caro: sobre o orçamento público em tempos de pandemia. In: Esquerda online, [s. l.], 19 mar. 2020. Disponivel em: https://esquerdaonline.com.br/2020/03/19/escassez-e-um-mito-vendido-caro-sobre-o-orcamento-publico-em-tempos-de-pandemia/. Acesso em: 20 set. 2020. 
BEHRING, Elaine; BOSCHETTI, Ivanete. "Transferência de renda", teto de gastos e oportunismo: para uma critica de esquerda. In: Esquerda online, [s. l.], 18 ago. 2020. Disponivel em: https://esquerdaonline.com. $\mathrm{br} / 2020 / 08 / 18 /$ transferencia-de-renda-teto-de-gastos-e-oportunismo-para-uma-critica-de-esquerda/. Acesso em: 24 set. 2020

BLYTH, Mark. Austeridade: a história de uma ideia perigosa. São Paulo: Autonomia Literária, 2008. CARDOSO JR, José. C.; RAIMUNDO, Licio DA C. Ilusões fiscais: equívocos do monetarismo e colapso histórico do liberalismo econômico. Revista Brasileira de Planejamento e Orçamento, v. 10, n. 1, p. 50-65, 2020.

CASTRO, Jorge; RIBEIRO, José; CHAVES, José; DUARTE, Bruno. Gasto Social Federal: prioridade macroeconômica no periodo 1995-2010. Brasilia: IPEA, setembro 2012. Nota técnica, no 11.

CISLAGHI, Juliana Fiuza. Do neoliberalismo de cooptação ao ultraneoliberalismo: respostas do capital à crise (partes 1, 2 e 3). In: Esquerda online, [s. l.], 08 jun. 2020. Disponivel em: https://esquerdaonline.com. $\mathrm{br/2020/06/08/do-neoliberalismo-de-cooptacao-}$ -ao-ultraneoliberalismo-respostas-do-capital-a-crise/. Acesso em: 24 jul. 2020.

DARDOT, Pierre. LAVAL, Christian. A nova razão do mundo: ensaio sobre a sociedade neoliberal. São Paulo: Boitempo, 2016

DWECK, Esther; GAIGER, Fernando; ROSSI, Pedro. Austeridade e desigualdade social no Brasil. In: ROSSI Pedro; DWECK, Esther; OLIVEIRA, Ana. (org.). Economia para poucos: impactos sociais da austeridade e alternativas para o Brasil. São Paulo: Autonomia Literária, 2018. p. 32-56.

FAGNANI, Eduardo. Austeridade e seguridade: a destruição do marco civilizatório. In: ROSSI, Pedro; DWECK, Esther; OLIVEIRA, Ana. (org.). Economia para poucos: impactos sociais da austeridade e alternativas para o Brasil. São Paulo: Autonomia Literária, 2018. p. 57-82.

GPMB. Global Preparedness monitoring board. Um mundo em peligro. Geneva: World Health Organization e World Bank Group, set. 2019. Informe anual sobre a preparación mundial para las emergencias sanitaris.

IPEA. Carta de conjuntura. Brasilia: IPEA, $3^{\circ}$. trimestre de 2020.

OLIVEIRA, Fabricio. Economia politica das finanças públicas no Brasil: um guia de leitura. São Paulo: Editora Hucitec, 2009. https://doi.org/10.1590/S010131572010000300011

PALOS, Aurélio et al. Nota Técnica Expositiva da EC 106/2020. Brasília: Câmara dos Deputados, 2020. Disponivel em: https://www2.camara.leg.br/orcamento-da-uniao/estudos/2020/NotaTecnicaConjuntaNo022020EC1062020.pdf. Acesso em: 24 set. 2020.

PISCITELLI, Roberto. B.; TIMBÓ, Maria. Z. F.; ROSA, Maria. B. Contabilidade pública: uma abordagem da administração financeira pública. 9a. ed. São Paulo: Editora Atlas, 2006
PUELLO-SOCARRÁS, José. Neoliberalismo, antineoliberalismo, nuevo neoliberalismo: episodios y trayectorias económico-políticas suramericanas (1973-2015). In: VILLAGRA, L. R. (coord.). Neoliberalismo en America Latina: crisis, tendencias y alternativas. Buenos Aires: Clacso, 2015. p. 19-42.

RODRIGUES, Júlia. Subsidios acerca da adequação orçamentária e financeira da Medida Provisória no 970, de 25 de maio de 2020. Brasília: Câmara dos Deputados, 2020.

ROSSI, Pedro; DWECK, Esther; OLIVEIRA, Ana. Economia para poucos: impactos sociais da austeridade e alternativas para o Brasil. São Paulo: Autonomia Literária, 2018.

SALVADOR, Evilasio da Silva. O desmonte do financiamento da seguridade social em contexto de ajuste fiscal. Serviço social \& Sociedade, São Paulo, v. 3, p. 426-446, 2017. https://doi.org/10.1590/0101-6628.117

SALVADOR, Evilasio. Fundo público e políticas sociais na crise do capitalismo. Serviço social \& Sociedade, São Paulo, v. 104, n. 104, p. 605-631, dez. 2010. https://doi. org/10.1590/S0101-66282010000400002

SALVADOR, Evilasio. Fundo público e financiamento da política de saúde em tempos de austeridade fiscal. In: ANDRADE, Roberta; PINHEIRO, Hamida; VALLINA, Kátia (org.). Campo Minado: as investidas do capital contra a Seguridade Social Brasileira. São Paulo: Alexa Cultural, 2020a. p. 31-53.

SALVADOR, Evilasio. Fundo público e conflito distributivo em tempos de ajuste fiscal no Brasil. In: CASTRO, Jorge Abrahão de; POCHMANN, Marcio (org.). Brasil: Estado Social contra a Barbárie. São Pulo: Fundação Perseu Abramo, 2020b. p. 367-388.

SANTOS, Reginaldo. A teoria das finanças públicas no contexto do capitalismo. São Paulo: Mandacaru, 2001.

STREECK, Wolfgang. Tempo comprado: a crise adiada do capitalismo democrático. São Paulo: Boitempo, 2018.

TEIXEIRA, Sandra. BOSCHETTI, Ivanete. O draconiano ajuste fiscal no Brasil e a expropriação de direitos da seguridade social. In: SALVADOR, Evilasio; BEHRING, Elaine; LIMA, Rita (org.). Crise do capital e fundo público: implicações para o trabalho, os direitos e a política social. São Paulo: Cortez Editora, 2019. p. 67-98.

VIEIRA, Fabíola; BENEVIDES, Rodrigo. Os impactos do novo regime fiscal para o financiamento do Sistema Único de Saúde e para a efetivação do direito à saúde no Brasil. Brasilia: IPEA, set. 2016. Nota técnica no. 28.

\section{Evilasio Salvador}

Doutor e Mestre em Política Social pela Universidade de Brasilia (UnB), em Brasilia, DF, Brasil. Economista pela Universidade Federal de Santa Catarina (UFSC); professor no Programa de Pós-Graduação em Politica Social e no Departamento de Serviço Social da UnB, em Brasilia. Bolsista de produtividade em pesquisa do CNPq. 


\section{Endereço para correspondência}

Evilasio Salvador

Universidade de Brasilia

Programa de Pós-Graduação em Política Social

ICC Norte - Mezanino

Campus Universitário Darcy Ribeiro - Asa Norte

70910900

Brasilia, DF, Brasil 